\title{
Perception of adult men and women regarding rape in Delhi, India
}

\author{
Binu Thomas*, Shilpa Sharma**, Veena Sharma**
}

\section{ABSTRACT:}

This study aimed at assessing the perception of adults towards rape. This descriptive study included 50 adults residing in Delhi, India, selected using convenient sampling technique. A structured interview schedule was used for data collection. Results revealed that people still do not have positive perceptions for rape victims. While majority of the respondents were females, yet many of them responded that a woman was responsible for rape in various situations. This study concluded that the issue of gender sensitization needs to be taken seriously by educationists, sociologists, politicians and common people alike.

Keywords: Rape, Perception, Responsibility, Psychological reactions

\section{INTRODUCTION}

Indian society is predominantly a patriarchal society. Deep-rooted attitudes that view women as having a lower status than men have meant that Indian girls and women face a barrage of threats ranging from human trafficking and sexual violence to child marriage and acid attacks, says Bhalla in her article, 'Reports of rape, dowry deaths, molestation rise in India in 2012'. According to Thomson Reuter's foundation, reports of crime against women such as rape, dowry, death, molestations and sexual harassment in India rose by $6.4 \%$ in 2012 from the previous year. The government said that the highest number of rapes was recorded in the capital city of Delhi. It is estimated that in India every 20 minutes 1 woman is raped.

Statistics showed that 244,270 crimes against women were reported to the police in 2012 compared with 228,650 in 2011, according to the National Crimes Records Bureau (NCRB) of India. According to reports in the media, a large number of rape cases in India go unreported. The NCRB India said the number of rapes in India rose by almost 3 percent to 24,923, with capital city of India, Delhi, reporting 06 rapes in 2012 - making it the city with the highest number of rapes in India.

Police attributes this rise in the crime against women to more women breaking their silence in the largely patriarchal, conservative India and coming forward to report the abuses they face. The crimes have not increased but more people are reporting.

(C) 2014 B Thomas, S Sharma, V Sharma; licensee IJIP. This is an Open Access Research distributed under the terms of the Creative Commons Attribution License (http://creativecommons.org/licenses/by/2.0), which permits unrestricted use, distribution, and reproduction in any Medium, provided the original work is properly cited. 
Research suggests that many female rape victims choose not to report the incident for fear of being held responsible Anderson maintains that 'victim blaming in cases of rape is so widely and uncritically practiced in western cultures that they could be accurately characterized as rape supportive or tolerant of rape. According to Burt myths surrounding rape are prevalent within society and contribute to female rape victims being blamed for the incident.

The National Crime Records Bureau's annual report of crime statistics also reports disturbing findings: A woman is raped somewhere in India every 20 minutes, and the number of children raped has increased by $336 \%$ in the past 10 years. As per the records, at least 12,857 women were raped in the Assam state in northeast of India between 2005 and May 2013. In the year 2012 , there were 24,923 cases of rape in India, according to the government's official statistics. That is about two per 100,000 Indians.

When a woman is raped, instead of blaming the rapist, it is victim who is blamed and there is victimization of the victim by everyone: the family, society, police and even the victim holds herself responsible for the rape inflicted on her. The victim is also blamed by the society and even the female members of the society. This culture of exemption from punishment is certainly one of the reasons rape has too often become the weapon of choice for frustrated young men who blame women, increasingly visible in the workplace, for their unemployment, and who hope to regain jobs by frightening women back home through sexual violence. The desire to blame women is fed by a cult of masculinity promoted by corporate and political leaders who serve as role models for the rest of society.

In the wake of the gang rape, which took place in the metropolitan city of Delhi, India, in December 2012, there was a lot of public outrage, widespread protests, discussions and debates, which brought to light the perceptions and reactions of the masses towards the victim, the rapist, the safety of women, the status of women in society, and laws related to rape and sexual offences. The most important change that has been made is the change in definition of rape under IPC. Although the Ordinance sought to change the word rape to sexual assault, in the Act the word 'rape' has been retained in Section 375, and was extended to include acts in addition to vaginal penetration. The bill expands the definition of rape to include not just penovaginal intercourse but the insertion of an object or any other body part into a woman's vagina, urethra or anus, and oral sex. But the remarkable fact here is that this point was added in the definition of rape according to Indian Penal Code in 'The criminal law (amendment) act' in the year 2013. This Act was deemed to have come into force on the $3^{\text {rd }}$ day of February 2013 only after the mass protests were held for the rape case that took place in the capital, New Delhi, in the month of December 2012.

In Indian society, people try to normalize, excuse, tolerate, or even condone rape. We have an environment in which rape is prevalent and in which sexual violence against women is normalized and excused in the media and popular culture. Rape culture is perpetuated through the use of misogynistic language, the objectification of women's bodies, and the glamorization of sexual 
violence, thereby creating a society that disregards women's rights and safety. "When rape victims are blamed for the crime committed against them, the message is the same i.e., the perpetrator was driven to assault by a skirt, or a date, or the oh-so-sexy invitation of being passed out drunk."

Reporting a rape puts the victim to scrutiny, both by the society and media. With the underreporting of rape cases, the rapists become repeat offenders and others get a message that they will not be penalized for committing rapes and sexual offences. Women who are victims of rape have to face many psychological consequences of rape, such as, low self esteem, guilt, post traumatic stress disorder, phobia and fear of men, depression (and sometimes even suicide), anxiety, nightmares etc., besides the physical and socio cultural consequences. These can be reduced if the society shows an attitude of acceptance, and non-judgment towards the rape victim. Therefore, it is very clear that there is a strong need to change the mindset or perspective of the society towards rape and rape victims. We need to see what the urban men and women think of the issues related to the rape, the rapist as well as the victim. With this information in the background, a cross-sectional survey was undertaken to assess the perception of adult men and women towards rape in Delhi, India. The objectives of the study were to assess the perception of young men and women towards rape in terms of responsibility for rape, reasons for rape, and for not reporting rape to police, and life after rape.

\section{METHODS}

The research approach adopted was quantitative, cross-sectional survey. The convenient sample consisted of 50 adults, both males and females, living in capital city of India, Delhi. The group consisted of students, office workers and homemakers who were friends, neighbors and acquaintances of the researcher. The adults were included in the study if they spoke and understood either Hindi (a language widely spoken across India) or English and were willing to participate in the study. Interviews were conducted with the help of a structured interview schedule. The structured interview schedule was developed by the researcher by review of related literature, consultation with experts in the field of Social Science, Psychiatric Nursing and with the help of books and journals. The content validity of the tool was established by giving to experts from the fields of Psychiatry, Social Science, Psychiatric nursing and Law. Participants had to answer the questions according to their perception regarding rape. In the study, perception meant the way in which something is regarded, understood or interpreted. Written consent to participate in the study was taken from each subject and all participants were assured of the confidentiality of the responses given by them and their anonymity. The subjects were approached for data collection at their homes during evenings or weekends, when they were free and as per their convenience.

Participants were interviewed by telephone or in person whichever was more convenient for them. The interview time averaged 25 minutes. Closed ended questions were devised to direct the participants to areas to explore their perception regarding rape. The areas included were: 
awareness about what accounts to rape, responsibility of rape, reasons for rape, reasons for not reporting rape to police, psychological reactions to rape and life of women after rape. Each area had different number of items as needed. Few questions like number of women raped in an hour, percentage of female rapes in which perpetrator is a stranger, etc. were also asked. These questions helped to check the knowledge of the participants regarding current rape statistics. For the questions related to statistics regarding rape, multiple options were given to choose from, and for questions in the area of 'responsibility for rape' three point rating scale were used in terms of 'total responsibility', 'partial responsibility' and 'no responsibility'. The rest of the questions were answered in terms of 'Agree/Disagree', 'Yes/No', 'True/False'. Participants were encouraged to answer all the questions according to their perception and not according to their knowledge based on books. The structured interview schedule was analyzed using descriptive statistics. Ms-Excel was used for analysis. The frequency and percentage were calculated for each item included in the structured interview schedule. The statistically analyzed data was tabulated.

\section{RESULTS}

Approximately three fourth of the participants of the study were females i.e. 37 (74\%) and $13(26 \%)$ were males. They were residents of various areas of capital city Delhi, India. The interview schedule consisted of 16 major areas regarding rape along with questions under each major area. In the first area, the participants were asked how many women they thought experienced rape in an hour. 20(40\%) answered 5 women were raped in an hour which is higher than current government rape statistics which says approximately 4 women are raped every hour in India (NCRB, 2012).

\section{Awareness about what amounts to rape}

The participants were asked what they thought could be called as rape. $41(82 \%)$ perceived that if the partner or husband forcefully indulged in sexual act, it could be equated to rape. 44(88\%) of the participants thought that in order for rape to take place it was not necessary for the victim to be a virgin. 39(78\%) subjects perceived that it was false to say that it is rape only if the perpetrator uses violence. 35(70\%) participants perceived that oral penetration could also amount to rape. $22(44 \%)$ participants perceived that the law required the victim to have physically resisted in order for rape to occur, which is quite interesting, in the light of the fact that the women at times 'give in' to the rape because they are beaten and threatened by the rapist that they would be killed if they resisted.

\section{Responsibility for rape on women}

The third area of the interview schedule was regarding the responsibility for rape on women. The findings are to be seen in the light of the fact that the majority of the study participants were 
females. $33(66 \%)$, i.e., more than half of the participants perceived that if the woman was intoxicated, she was responsible for rape. 39 (78\%), i.e., more than three fourth participants thought that if a woman had started a sexual or seductive act on the man, she was responsible for rape. $28(56 \%)$ participants thought that a woman was responsible for rape if she behaved in a flirtatious manner. 36(72\%) said that a woman was not responsible for rape if she had had numerous sexual partners. $39(78 \%)$ said that if the woman was out late at night she was not responsible for rape.26(52\%), i.e., more than half of the participants thought that if the woman was wearing revealing clothes she was responsible for being raped.

The participants were asked if they thought that in some circumstances women who were raped deserved to get raped. $48(96 \%)$ of the participants said a categorical 'No'. This figure is in contrast with previously asked questions related to responsibility for rape where many a respondent $(>50 \%)$ had said that a women who was intoxicated, behaved in a flirtatious manner and wore revealing clothes invites rape for herself. 2(4\%) said 'Yes' to the question on whether women who were raped deserved to be raped. The two participants who said 'Yes' were females. When the respondents were asked in what percentage of female rape they thought the perpetrator was a stranger, $16(32 \%)$ said that it was so in $50 \%$ of female rapes.

\section{Reasons for rape}

$37(74 \%)$ participants perceived that once a man was sexually aroused, he could not prevent his actions, was one of the reasons for rape to occur. 21(42\%) participants thought that the men who raped women were mentally ill. 16(32\%) participants agreed that flirtatious behavior and inappropriate dress of women were reasons for rape. 22(44\%) of the participants perceived that men raped women to gain power and control. 43(86\%) participants disagreed that men raped women because women fail to clearly say 'No'. 47(94\%) participants disagreed that most women secretly wanted to be raped and men were aware of this. 29(58\%) participants thought that men raped women because they enjoyed inflicting fear and pain on women. When the participants were asked whether they thought that if women were more careful not to 'lead men on' there would be fewer instances of rape, 24(48\%), i.e., almost half said 'Yes'. In the next question, the participants were asked if they thought that in rape cases the court should take into account factors such as how the women was dressed and the manner in which she was behaving. 24(48\%), i.e., almost half of the participants said 'Yes'. When the participants were asked about what they thought on how many women reported rape to the police, more than three fourth, that is, 39(78\%) said only some of them reported rape to the police.

\section{Reasons for not reporting rape to police}

In the next question, the participants were asked the reason for not reporting rape to police. Majority of the participants (ranging between 58\% to 96\%) thought that women did not report 
rape to police because of many reasons such as, they think that they will not be believed, rather they will be blamed for it, they were ashamed of themselves, they blamed themselves for rape and because they feared that it will bring on a bad name to their families. 44(88\%) participants perceived that fear of the perpetrator was one of the reasons why women did not report rape to police. This data showed the mistrust which women have on the law and order of India, as the government says it ensures safety for every woman. 22(44\%) participants perceived that women did not report rape to police because they did not consider themselves to have been raped. $45(90 \%)$ participants said some of the rape cases reported to police were false allegations.

\section{Psychological reactions}

Majority of the participants ( $72 \%$ to $100 \%$ ) perceived that women experienced low self-esteem, depression, fear of men, loss of confidence, chronic headaches and menstrual irregularities as a result of rape. When the participants were asked if they thought women exaggerated how much rape affects them, 22(44\%), i.e., almost half of the participants said 'Yes'. 44(88\%) subjects perceived that rape was not less distressing for women when the perpetrator was someone they knew.

\section{Life after rape}

When the participants were asked as to how according to them the women should lead her life after she was raped, all the participants $(100 \%)$ disagreed that she should marry the perpetrator, live her life with a stigma, should not get married to anyone, should end her life and should think that there is nothing left in her life. $48(96 \%)$ participants perceived that women who were victims of rape should bounce back to her earlier life.

\section{DISCUSSION}

The results of the study revealed that people still do not have positive perceptions of rape and rape victims. While majority of the respondents were females, yet many of them perceived that a woman was responsible for rape if she was intoxicated, wore revealing clothes, was out late at night, behaved in a flirtatious manner or started a sexual or seductive act on man. Two of the women even reported that there were certain circumstances in which women who are raped deserved to be raped. The study findings cannot be generalized because of the smaller sample size.

This clearly shows that although there were countrywide protests and debates in the wake of the incidents of rapes and subsequently changes in Indian laws and legislations pertaining to rape happened, yet change in the mindset of the people is yet to take place. The stereotypes related to rape and women inviting rape on them, 'leading men on' are not yet broken. The issue of gender sensitization in a patriarchal society still needs to be taken seriously by educationists, sociologists, 
politicians and common people alike. Respondents in the study believed that women did not report rape to police because of various reasons such as they feared that they will not be believed, others will blame them, they were ashamed of themselves, they blamed themselves for rape, they feared that it will bring a bad name to their families or because they were fearful of the perpetrator.

This also speaks a lot about the perceptions and beliefs of people that rapes are not reported and not to be reported either, as there are hindrances in acceptance of rape victims in our society. This also shows that the statistics and data related to rape are not actual data. Complete reporting of rapes and crimes against women can happen only when women have the assurance and knowledge that they would not be judged and victimized for being the victims and that the guilty would be brought to book. When the respondents were asked in what percentage of female rape they thought the perpetrator was a stranger, $16(32 \%)$ said that it was so in $50 \%$ of female rapes..This answer was not corresponding with the rape statistics of India (NCRB, 2009), which says that in more than $90 \%$ of the females rapes, the perpetrator was not a stranger. So, this data points out that the female members of Indian society need to be more cautious of the people they know rather than the strangers.

Respondents in this study also reported that women experienced low self esteem, depression, fear of men, loss of confidence, chronic headaches, anxiety and menstrual irregularities as consequences of rape, although they thought that victims of rape should bounce back to life even with the far reaching psychological and other consequences of rape. Thankfully, this shows that people do not have a stereotypical thinking that rape means 'end of life' for a woman and that she would be better off 'dead' than alive after she has been raped. This gives a hope that people have started to think positively for life after rape for rape victims.

\section{Implications for Nursing Practice}

The study has implications for nursing practice as well. Nurses receive the rape victims when they are brought to the hospital by police, family members or other social agencies. Nurses are the part of a larger society and their perceptions about rape and rape victims are bound to be colored by the perceptions generally prevailing in society and culture. Hence, how they interact with, and care for rape victims is also bound to be similarly affected. In India, there is a need for sensitization of the people towards gender specific crimes, such as molestations, sexual assaults and rapes, with special emphasis on not victimizing the victim. Nurses while interacting with rape victims in emergency department of the hospital or ward, need to show an attitude of acceptance, empathy and respectful and dignified approach towards the rape victims without being judgmental, biased and misogynistic. For this, we need to gauge the perception of common people in society and bring changes in their mindsets so that the society and health care system is sensitive towards the needs of the rape victims. Community health nurses can be the change 
agent in bringing about this change in attitudes and perceptions of the communities at large by reaching out to people through mass education.

\section{REFERENCES:}

1. Anderson, I., and Dohrety, K. (2008). Accounting for rape: Psychology, Feminism and Discourse Analysis in the Study of Sexual Violence. Sussex: Routledge

2. Anurag K. (2013 January 08). The stigma and blame attached to rape survivors in India. Reuters. Retrieved from: Http://Www.Hrw.Org/News/2013/01/08/Stigma-And-Blame-Attached-Rape-SurvivorsIndia

3. Bhalla N. (2013, June 14). Reports of rape, dowry deaths, and molestations rise in India in 2012. Thomson Reuters Foundation. Retrieved from http://in.reuters.com/article/2013/06/14/india-rape-women-2012-reportidINDEE95D0B920130614

4. Gupta R. (2013, August 28). Victims blamed in India's rape culture. CNN. Retrieved from http://edition.cnn.com/2013/08/27/opinion/gupta-india-rape-culture/

5. Majumdar S. (2012, December 29) Protests in India after Delhi gang-rape victim dies. BBC. Retrieved from http://www.bbc.com/news/world-asia-india-20863707

6. Marshall University, Women's Center. (2013, April 09).. Rape Culture. Retrieved from: http://www.marshall.edu/wpmu/wcenter/sexual-assault/rape-culture

7. Pothen, P. K. , 2008-07-31 "A Sociological Study Of The Problem Of Rape In India With Particular Reference To Central India" Paper presented at the annual meeting of the American Sociological Association Annual Meeting, Sheraton Boston and the Boston Marriott Copley Place, Boston, MA Online <PDF>. 2013-1214 from http://citation.allacademic.com/meta/p242646_index.html

8. Pranjal B. (2013, September 03). Assam records 800 rapes in seven months. The National Network. Retrieved from:

http://articles.timesofindia.indiatimes.com/2013-09-03/guwahati/41725290_1_assamrecords-national-crime-records-bureau-morigaon

9. Rape and molestation violence against women increases by six percent in India. (2013 June 16). Catholic online ( News Consortium) Retrieved from: http://www.catholic.org/international/international_story.php?id=51381

10. Rape statistics around the world. (2012, September 11). Indiatribune.com. Retrieved from: http://www.indiatribune.com/index.php?option=com_content\&view=article\&id=10195:rap e-statistics-around-the-world-\&catid=107: coverpage $\&$ Itemid $=471$

11. Shuchitra M. (2013, March 17). Indian rape victim's father says he wants her named. Thomason Reuters Foundation. Retrieved from: http://in.reuters.com/article/2013/01/06/us-india-rape-idUSBRE90500B20130106

12. Williams, L.S. (1984). The classic rape: When do victims report? Social Problems 31(4), 459-467. 